\title{
Strong and weak convergence of an implicit iterative process for pseudocontractive semigroups in Banach space
}

\author{
Jing Quan ${ }^{1 *}$, Shih-sen Chang ${ }^{2}$ and Min Liu
}

\author{
* Correspondence: \\ quanjingcq@163.com \\ 'Department of Mathematics, Yibin \\ University, Yibin, Sichuan 644000, \\ China \\ Full list of author information is \\ available at the end of the article
}

\begin{abstract}
The purpose of this article is to study the strong and weak convergence of implicit iterative sequence to a common fixed point for pseudocontractive semigroups in Banach spaces. The results presented in this article extend and improve the corresponding results of many authors.
\end{abstract}

\section{Introduction and preliminaries}

Throughout this article we assume that $E$ is a real Banach space with norm $\|\cdot\|$, $E^{*}$ is the dual space of $E ;\langle\cdot, \cdot\rangle$ is the duality pairing between $E$ and $E^{*} ; C$ is a nonempty closed convex subset of $E ; \mathbb{N}$ denotes the natural number set; $\mathfrak{R}^{+}$is the set of nonnegative real numbers; The mapping $J: E \rightarrow 2^{E^{*}}$ defined by

$$
J(x)=\left\{f^{*} \in E^{*}:\left\langle x, f^{*}\right\rangle=\|x\|^{2} ;\left\|f^{*}\right\|=\|x\|, \quad x \in E\right\}
$$

is called the normalized duality mapping. We denote a single valued normalized duality mapping by $j$.

Let $T: C \rightarrow C$ be a nonlinear mapping; $F(T)$ denotes the set of fixed points of mapping $T$, i.e., $F(T):=\{x \in C, x=T x\}$. We use " $\rightarrow$ " to stand for strong convergence and " $\rightarrow$ " for weak convergence. For a given sequence $\left\{x_{n}\right\} \subset C$, let $\omega_{w}\left(x_{n}\right)$ denote the weak $\omega$-limit set.

Recall that $T$ is said to be pseudocontractive if for all $x, y \in C$, there exists $j(x-y) \in J$ $(x-y)$ such that

$$
\langle T x-T y, j(x-y)\rangle \leq\|x-y\|^{2}
$$

$T$ is said to be strongly pseudocontr active if there exists a constant $\alpha \in(0,1)$, such that for any $x, y \in C$, there exists $j(x-y) \in J(x-y)$

$$
\left\langle T x-T y, j(x-y) \leq \alpha\|x-y\|^{2} .\right.
$$

In recent years, many authors have focused on the studies about the existence and convergence of fixed points for the class of pseudocontractions. Especially in 1974, Deimling [1] proved the following existence theorem of fixed point for a continuous and strong pseudocontraction in a nonempty closed convex subset of Banach spaces.

(c) 2012 Quan et al; licensee Springer. This is an Open Access article distributed under the terms of the Creative Commons Attribution License (http://creativecommons.org/licenses/by/2.0), which permits unrestricted use, distribution, and reproduction in any medium, provided the original work is properly cited. 
Theorem D. Let $E$ be a Banach space, $C$ be a nonempty closed convex subset of $E$ and $T: C \rightarrow C$ be a continuous and strong pseudocontraction. Then $T$ has a unique fixed point in $C$.

Recently, the problems of convergence of an implicit iterative algorithm to a common fixed point for a family of nonexpansive mappings or pseudocontractive mappings have been considered by several authors, see [2-5]. In 2001, Xu and Ori [2] firstly introduced an implicit iterative $x_{n}=\alpha_{n} x_{n-1}+\left(1-\alpha_{n}\right) T_{n} x_{n}, n \in \mathbb{N}, x_{0} \in C$ for a finite family of nonexpansive mappings $\left\{T_{i}\right\}_{i=1}^{N}$ and proved some weak convergence theorems to a common fixed point for a finite family of nonexpansive mappings in a Hilbert space. In 2004, Osilike [3] improved the results of Xu and Ori [2] from nonexpansive mappings to strict pseudocontractions in the framework of Hilbert spaces. In 2006, Chen et al. [4] extended the results of Osilike [3] to more general Banach spaces.

On the other hand, the convergence problems of semi-groups have been considered by many authors recently. Suzuki [6] considered the strong convergence to common fixed points of nonexpansive semigroups in Hilbert spaces. Xu [7] gave strong convergence theorem for contraction semigroups in Banach spaces. Chang et al. [8] proved the strong convergence theorem for nonexpansive semi-groups in Banach space. He also studied the weak convergence problems of the implicit iteration process for Lipschitzian pseudocontractive semi-groups in the general Banach spaces [9]. The pseudocontractive semi-groups is defined as follows.

Definition 1.1 (1) One-parameter family $\mathbf{T}:=\{T(t): t \geq 0\}$ of mappings from $C$ into itself is said to be a pseudo-contraction semigroup on $C$, if the following conditions are satisfied:

(a). $T(0) x=x$ for each $x \in C$;

(b). $T(t+s) x=T(s) T(t)$ for any $t, s \in \mathfrak{R}^{+}$and $x \in C$;

(c). For any $x \in C$, the mapping $t \rightarrow T(t) x$ is continuous;

(d). For all $x, y \in C$, there exists $j(x-y) \in J(x-y)$ such that

$$
\left\langle T(t) x-T(t) y, j(x-y) \leq\|x-y\|^{2}, \quad \text { for any } t>0 .\right.
$$

(2) A pseudo-contraction semigroup of mappings from $C$ into itself is said to be a Lipschitzian if the condition (a)-(d) and following condition (f) are satisfied.

(f) there exists a bounded measurable function $L:[0, \infty) \rightarrow[0, \infty)$ such that for any $x$, $y \in C$,

$$
\|T(t) x-T(t) y\| \leq L(t)\|x-y\|
$$

for any $t>0$. In the sequel, we denote it by

$$
L=\sup _{t \geq 0} L(t)<\infty
$$

Cho et al. [10] considered viscosity approximations with continuous strong pseudocontractions for a pseudocontraction semigroup and prove the following theorem.

Theorem Cho. Let $E$ be a real uniformly convex Banach space with a uniformly Gâteaux differentiable norm, and $C$ be a nonempty closed convex subset of $E$. Let $T(t)$ : $t \geq 0$ be a strongly continuous $L$-Lipschitz semigroup of pseudocontractions on $C$ such that $\Omega \neq \emptyset$, where $\Omega$ is the set of common fixed points of semi-group $T(t)$. Let $f: C \rightarrow$ 
$C$ be a fixed bounded, continuous and strong pseudocontraction with the coefficient $\alpha$ in $(0,1)$, let $\alpha_{n}$ and $t_{n}$ be sequences of real numbers satisfying $\alpha_{n} \in(0,1), t_{n}>0$, and $\lim _{n \rightarrow \infty} t_{n}=\lim _{n \rightarrow \infty} \frac{\alpha_{n}}{t_{n}}=0$; Let $\left\{x_{n}\right\}$ be a sequence generated in the following manner:

$$
x_{n}=\left(1-\alpha_{n}\right) f\left(x_{n}\right)+\alpha_{n} T\left(t_{n}\right) x_{n}, \quad \forall n \geq 1 .
$$

Assume that $L I M|| T(t) x_{n}-T(t) x^{*}\|\leq\| x_{n}-x^{*} \|, \forall x^{*} \in K, t \geq 0$, where $K:=\left\{x^{*} \in C\right.$ : $\left.\Phi\left(x^{*}\right)=\min _{x \in C} \Phi(x)\right\}$ with $\Phi(x)=L I M|| x_{n}-x \|^{2}, \forall x \in C$. Then $x_{n}$ converges strongly to $x^{*} \in \Omega$ which solves the following variational inequality: $\left\langle(I-f) x^{*}, j\left(x^{*}-x\right)\right\rangle \leq 0, \forall x$ $\in \Omega$.

Qin and Cho [11] established the theorems of weak convergence of an implicit iterative algorithm with errors for strongly continuous semigroups of Lipschitz pseudocontractions in the framework of real Banach spaces.

Theorem $\mathbf{Q}$. Let $\mathrm{E}$ be a reflexive Banach space which satisfies Opial's condition and $\mathrm{K}$ a nonempty closed convex subset of $\mathrm{E}$. Let $\mathcal{T}:=\{T(t): t \geq 0\}$ be a strongly continuous semigroup of Lipschitz pseudocontractions from $K$ into itself with $\mathfrak{F}:=\bigcap_{t \geq 0} F(T(t)) \neq \emptyset$; Assume that $\sup _{t \geq 0}\{L(t)\}<\infty$, where $L(t)$ is the Lipschitz constant of the mapping $T(t)$. Let $\left\{x_{n}\right\}$ be a sequence generated by the following iterative process:

$$
x_{0} \in K ; x_{n}=\alpha_{n} x_{n-1}+\beta_{n} T\left(t_{n}\right) x_{n}+\gamma_{n} u_{n} ; \quad \forall n \geq 1 ;
$$

where $\left\{\alpha_{n}\right\},\left\{\beta_{n}\right\},\left\{\gamma_{n}\right\}$ are sequences in $(0,1),\left\{t_{n}\right\}$ is a sequence in $(0, \infty)$ and $\left\{u_{n}\right\}$ is a bounded sequence in $\mathrm{K}$. Assume that the following conditions are satisfied:

(a) $\alpha_{n}+\beta_{n}+\gamma_{n}=1$

(b) $\lim _{n \rightarrow \infty} t_{n}=\lim _{n \rightarrow \infty} \frac{\alpha_{n}+\gamma_{n}}{t_{n}}=0$.

Then the sequence $\left\{x_{n}\right\}$ generated in (7) converges weakly to a common fixed point of the semigroup $\mathcal{T}:=\{T(t): t \geq 0\}$;

Agarwal et al. [12] studied strongly continuous semigroups of Lipschitz pseudocontractions and proved the strong convergence theorems of fixed points in an arbitrary Banach space based on an implicit iterative algorithm.

Theorem $\mathrm{A}$. Let $\mathrm{E}$ be an arbitrary Banach space and $K$ a nonempty closed convex subset of $E$. Let $\mathcal{T}:=\{T(t): t \geq 0\}$ be a strongly continuous semigroup of Lipschitz pseudocontractions from $K$ into itself with $\mathfrak{F}:=\bigcap_{t \geq 0} F(T(t)) \neq 0$. Assume that $\sup _{t \geq 0}\{L$ $(t)\}<\infty$, where $L(t)$ is the Lipschitz constant of the mapping $T(t)$. Let $\left\{x_{n}\right\}$ be a sequence in

$$
x_{0} \in K ; x_{n}=\alpha_{n} x_{n-1}+\beta_{n} T\left(t_{n}\right) x_{n}+\gamma_{n} u_{n} ; \quad \forall n \geq 1,
$$

where $\left\{\alpha_{n}\right\},\left\{\beta_{n}\right\},\left\{\gamma_{n}\right\}$ are sequences in $(0,1)$ such that $\alpha_{n}+\beta_{n}+\gamma_{n}=1,\left\{t_{n}\right\}$ is a sequence in $(0, \infty)$ and $\left\{u_{n}\right\}$ is a bounded sequence in K. Assume that $\lim _{n \rightarrow \infty} \frac{\gamma_{n}}{\alpha_{n}+\gamma_{n}}<\infty, \lim _{n \rightarrow \infty} \frac{\gamma_{n}}{\alpha_{n}+\gamma_{n}}<\infty$ and there is a nondecreasing function $f:(0$, $\infty) \rightarrow(0, \infty)$ with $f(0)=0$ and $f(t)>0$ for all $t \in(0, \infty)$ such that, for all $x \in C$, $\sup \{\|x-T(t) x\|: t \geq 0\} \geq f(\operatorname{dist}(x, \mathfrak{F}))$. Then the sequence $\left\{x_{n}\right\}$ converges strongly to a common fixed point of the semigroup $\mathcal{T}:=\{T(t): t \geq 0\}$. 
The purpose of this article is to prove the strong and weak convergence of implicit iterative process

$$
x_{n}=\left(1-\alpha_{n}\right) x_{n-1}+\alpha_{n} T\left(t_{n}\right) x_{n}, \quad n \in \mathbb{N}, \quad x_{0} \in C
$$

for a pseudocontraction semigroup $\mathbf{T}:=\{T(t): t \geq 0\}$ in the framework of Banach spaces, which improves and extends the corresponding results of many author's. We need the following Lemma.

Lemma 1.1 [9] Let E be a real reflexive Banach space with Opial condition. Let C be a nonempty closed convex subset of $E$ and $T: C \rightarrow C$ be a continuous pseudocontractive mapping. Then $I-T$ is demiclosed at zero, i.e., for any sequence $\left\{x_{n}\right\} \subset E$, if $x_{n} \rightarrow y$ and $\left\|(I-T) x_{n}\right\| \rightarrow 0$, then $(I-T) y=0$.

\section{Main results}

Theorem 2.1 Let E be a real Banach space and $C$ be a nonempty compact convex subset of E. Let $\mathbf{T}:=\{T(t): t \geq 0\}: C \rightarrow C$ be a Lipschitian and pseudocontraction semigroup defined by Definition 1.1 with a bounded measurable function $L:[0, \infty) \rightarrow[0, \infty)$. Suppose $F(\mathrm{~T}):=\bigcap_{t \geq 0} F(T(t)) \neq \emptyset$. Let $\alpha_{n}$ and $t_{n}$ be sequences of real numbers satisfying $t_{n}>0, \alpha_{n} \in[a, 1) \subset(0,1)$ and $\lim _{n \rightarrow \infty} \alpha_{n}=1$. Then the sequence $\left\{x_{n}\right\}$ defined by (9) converges strongly to a common fixed point $x^{*} \in F(\mathbf{T})$ in $C$.

Proof. We divide the proof into five steps.

$(I)$. The sequence $\left\{x_{n}\right\}$ defined by $x_{n}=\left(1-\alpha_{n}\right) x_{n-1}+\alpha_{n} T\left(t_{n}\right) x_{n}, n \in \mathbb{N}, x_{0} \in C$ is well defined.

In fact for all $n \in \mathbb{N}$, we define a mapping $S_{n}$ as follows:

$$
S_{n} x=\left(1-\alpha_{n}\right) x_{n-1}+\alpha_{n} T\left(t_{n}\right) x, \quad n \in, \quad \forall x \in C .
$$

Then we have

$$
\left\langle S_{n} x-S_{n} y_{1} j(x-y)\right\rangle=\alpha_{n}\left\langle T\left(t_{n}\right) x-T\left(t_{n}\right) y \quad j(x-y)\right\rangle \leq \alpha_{n}\|x-y\|^{2} .
$$

So $S_{n}$ is strongly pseudo-contraction, thus from Theorem $D$, there exists a point $x_{n}$ such that $x_{n}=\left(1-\alpha_{n}\right) x_{n-1}+\alpha_{n} T\left(t_{n}\right) x_{n}$, that is the sequence $\left\{x_{n}\right\}$ defined by $x_{n}=(1-$ $\left.\alpha_{n}\right) x_{n-1}+\alpha_{n} T\left(t_{n}\right) x_{n}, n \in \mathbb{N}, x_{0} \in C$ is well defined.

(II). Since the common fixed-point set $F(\mathbf{T})$ is nonempty let $p \in F(\mathbf{T})$. For each $p \in$ $F(\mathbf{T})$, we prove that $\lim _{n \rightarrow \infty}|| x_{n}-p \|$ exists.

In fact

$$
\begin{aligned}
\left\|x_{n}-p\right\|^{2} & =\left\langle x_{n}-p, \quad j\left(x_{n}-p\right)\right\rangle \\
& =\left\langle\left(1-\alpha_{n}\right)\left(x_{n-1}-p\right)+\alpha_{n}\left(T\left(t_{n}\right) x_{n}-p\right), \quad j(x-p)\right\rangle \\
& \leq\left(1-\alpha_{n}\right)\left\|x_{n-1}-p\right\|\left\|x_{n}-p\right\|+\alpha_{n}\left\|x_{n}-p\right\|^{2} .
\end{aligned}
$$

So we get $\left\|x_{n}-p\right\| \leq\left(1-\alpha_{n}\right)\left\|x_{n-1}-p\right\|+\alpha_{n}\left\|x_{n}-p\right\|$, that is

$$
\left\|x_{n}-p\right\| \leq\left\|x_{n-1}-p\right\| \text {. }
$$

This implies that the limit $\lim _{n \rightarrow \infty}\left\|x_{n}-p\right\|$ exists.

(III). We prove $\lim _{n \rightarrow \infty}\left\|T\left(t_{n}\right) x_{n}-x_{n}\right\|=0$.

The sequence $\left\{\left\|x_{n}-p\right\|_{n \in \mathbb{N}}\right\}$ is bounded since $\lim _{n \rightarrow \infty}\left\|x_{n}-p\right\|$ exists, so the sequence $\left\{x_{n}\right\}$ is bounded. Since 


$$
\begin{aligned}
\left\|T\left(t_{n}\right) x_{n}\right\| & =\left\|\frac{x_{n}-\left(1-\alpha_{n}\right) x_{n-1}}{\alpha_{n}}\right\| \\
& \leq \frac{\left\|x_{n}\right\|}{\alpha_{n}}+\frac{\left(1-\alpha_{n}\right)\left\|x_{n-1}\right\|}{\alpha_{n}} \\
& \leq \frac{\left\|x_{n}\right\|}{a}+\frac{\left(1-\alpha_{n}\right)\left\|x_{n-1}\right\|}{a},
\end{aligned}
$$

This shows that $\left\{T\left(t_{n}\right) x_{n}\right\}$ is bounded. In view of

$$
\left\|x_{n}-T\left(t_{n}\right) x_{n}\right\|=\left\|\left(1-\alpha_{n}\right)\left(x_{n-1}-T\left(t_{n}\right) x_{n}\right)\right\|=\left\|1-\alpha_{n}\right\| \cdot\left\|x_{n-1}-T\left(t_{n}\right) x_{n}\right\|
$$

and condition $\lim _{n \rightarrow \infty} \alpha_{n}=1$, we have

$$
\lim _{n \rightarrow \infty}\left\|T\left(t_{n}\right) x_{n}-x_{n}\right\|=0 .
$$

(IV). Now we prove that for all $t>0, \lim _{n \rightarrow \infty}\left\|T(t) x_{n}-x_{n}\right\|=0$.

Since pseudocontraction semigroup $\mathbf{T}:=\{T(t): t \geq 0\}$ is Lipschitian, for any $k \in \mathbb{N}$,

$$
\begin{aligned}
& \left\|T\left((k+1) t_{n}\right) x_{n}-T\left(k t_{n}\right) x_{n}\right\| \\
= & \left\|T\left(k t_{n}\right) T\left(t_{n}\right) x_{n}-T\left(k t_{n}\right) x_{n}\right\| \\
\leq & L\left(k t_{n}\right)\left\|T\left(t_{n}\right) x_{n}-x_{n}\right\| \\
\leq & L\left\|T\left(t_{n}\right) x_{n}-x_{n}\right\| .
\end{aligned}
$$

Because $\lim _{n \rightarrow \infty}\left\|T\left(t_{n}\right) x_{n}-x_{n}\right\|=0$, so for any $k \in \mathbb{N}$,

$$
\lim _{n \rightarrow \infty}\left\|T\left((k+1) t_{n}\right) x_{n}-T\left(k t_{n}\right) x_{n}\right\|=0 .
$$

Since

$$
\begin{aligned}
& \left\|T(t) x_{n}-T\left(\left[\frac{t}{t_{n}}\right] t_{n}\right) x_{n}\right\| \\
= & \left\|T\left(\left[\frac{t}{t_{n}}\right] t_{n}\right) T\left(t-\left[\frac{t}{t_{n}}\right] t_{n}\right) x_{n}-T\left(\left[\frac{t}{t_{n}}\right] t_{n}\right) x_{n}\right\| \\
\leq & L\left\|T\left(t-\left[\frac{t}{t_{n}}\right] t_{n}\right) x_{n}-x_{n}\right\|
\end{aligned}
$$

and $T(\cdot)$ is continuous, we have

$$
\lim _{n \rightarrow \infty}\left\|T\left(\left[\frac{t}{t_{n}}\right] t_{n}\right) x_{n}-T(t) x_{n}\right\|=0 .
$$

So from

$$
\begin{aligned}
& \left\|x_{n}-T(t) x_{n}\right\| \\
& \leq \sum_{k=0}^{\left.\frac{t}{t_{n}}\right]-1}\left\|T\left((k+1) t_{n}\right) x_{n}-T\left(k t_{n}\right) x_{n}\right\|+\left\|T\left(\left[\frac{t}{t_{n}}\right] t_{n}\right) x_{n}-T(t) x_{n}\right\|,
\end{aligned}
$$

and $\lim _{n \rightarrow \infty}\left\|T\left((k+1) t_{n}\right) x_{n}-T\left(k t_{n}\right) x_{n}\right\|=0$ as well as $\lim _{n \rightarrow \infty}\left\|T\left(\left[\frac{t}{t_{n}}\right] t_{n}\right) x_{n}-T(t) x_{n}\right\|=0$, we can get 


$$
\lim _{n \rightarrow \infty}\left\|T(t) x_{n}-x_{n}\right\|=0 .
$$

$(V)$. We prove $\left\{x_{n}\right\}$ converges strongly to an element of $F(\mathbf{T})$.

Since $C$ is a compact convex subset of $E$, we know there exists a subsequence $\left\{x_{n_{j}}\right\} \subset\left\{x_{n}\right\}$, such that $x_{n_{j}} \rightarrow x \in C$. So we have $\lim _{j \rightarrow \infty}\left\|T(t) x_{n_{j}}-x_{n_{j}}\right\|=0$ from $\lim _{n \rightarrow \infty}\left\|T(t) x_{n}-x_{n}\right\|=0$, and

$$
\|x-T(t) x\|=\lim _{j \rightarrow \infty}\left\|T(t) x_{n_{j}}-x_{n_{j}}\right\|=0 .
$$

This manifests that $x \in F(\mathbf{T})$. Because for any $p \in F(\mathbf{T}), \lim _{n \rightarrow \infty}\left\|x_{n}-p\right\|$ exists, and $\lim _{n \rightarrow \infty}\left\|x_{n}-x\right\|=\lim _{j \rightarrow \infty}\left\|x_{n_{j}}-x\right\|=0$, we have that $\left\{x_{n}\right\}$ converges strongly to an element of $F(\mathbf{T})$. This completes the proof of Theorem 2.1.

Theorem 2.2 Let $E$ be a reflexive Banach space satisfying the Opial condition and $C$ be a nonempty closed convex subset of $E$. Let $\mathbf{T}:=\{T(t): t \geq 0\}: C \rightarrow C$ be a Lipschitian and pseudocontraction semigroup defined by Definition 1.1 with a bounded measurable function L: $[0, \infty) \rightarrow[0, \infty)$. Suppose $F(T):=\bigcap_{t \geq 0} F(T(t)) \neq 0$. Let $\alpha_{n}$ and $t_{n}$ be sequences of real numbers satisfying $t_{n}>0, \alpha_{n} \in[a, 1) \subset(0,1)$ and $\lim _{n \rightarrow \infty} \alpha_{n}=1$. Then the sequence $\left\{x_{n}\right\}$ defined by $x_{n}=\left(1-\alpha_{n}\right) x_{n-1}+\alpha_{n} T\left(t_{n}\right) x_{n}, x_{0} \in C, n \in \mathbb{N}$, converges weakly to a common fixed point $x^{*} \in F(T)$ in $C$.

Proof. It can be proved as in Theorem 2.1, that for each $p \in F(T)$, the $\operatorname{limit}_{n \rightarrow \infty}$ $\left\|x_{n}-p\right\|$ exists and $\left\{T\left(t_{n}\right) x_{n}\right\}$ is bounded, for all $t>0, \lim _{n \rightarrow \infty}\left\|T(t) x_{n}-x_{n}\right\|=0$. Since $E$ is reflexive, $C$ is closed and convex, $\left\{x_{n}\right\}$ is bounded, there exist a subsequence $\left\{x_{n_{j}}\right\} \subset\left\{x_{n}\right\}$ such that $x_{n_{j}} \rightarrow x$. For any $t>0$, we have $\lim _{n_{j} \rightarrow \infty}\left\|T(t) x_{n_{j}}-x_{n_{j}}\right\|=0$. By Lemma 1.1, $x \in F(T(t)), \forall t>0$. Since the space $E$ satisfies Opial condition, we see that $\omega_{w}\left(x_{n}\right)$ is a singleton. This completes the proof.

Remark 2.1 There is no other condition imposed on $t_{n}$ in the Theorems 2.1 and 2.2 except that in the definition of pseudo-contraction semigroups. So our results improve corresponding results of many authors such as [10-12], of cause extend many results in [4-8].

Acknowledgements

This work was supported by National Research Foundation of Yibin University (No.2011B07).

Author details

${ }^{1}$ Department of Mathematics, Yibin University, Yibin, Sichuan 644000, China ${ }^{2}$ College of Statistics and Mathematics, Yunnan University of Finance and Economics, Kunming, Yunnan 650221, China

\section{Authors' contributions}

All the authors contributed equally to the writing of the present article. And they also read and approved the final manuscript.

\section{Competing interests}

The authors declare that they have no competing interests.

Received: 4 November 2011 Accepted: 15 February 2012 Published: 15 February 2012

\section{References}

1. Deimling, K: Zeros of accretive operators. Manuscripta Math. 13, 365-374 (1974). doi:10.1007/BF01171148

2. $\mathrm{Xu}, \mathrm{HK}$, Ori, RG: An implicit iteration process for nonexpansive mappings. Numer Funct Anal Optim. 22, 767-773 (2001). doi:10.1081/NFA-100105317

3. Osilike, MO: Implicit iteration process for common fixed points of a finite family of strictly pseudocontractive maps. J Math Anal Appl. 294, 73-81 (2004). doi:10.1016/j.jmaa.2004.01.038

4. Chen, RD, Song, YS, Zhai, HY: Convergence theorems for implicit iteration press for a finite family of continuous pseudocontractive mappings. J Math Anal Appl. 314, 701-709 (2006). doi:10.1016/j.jmaa.2005.04.018 
5. Zhou, HY: Convergence theorems of common fixed points for a finite family of Lipschitzian pseudocontractions in Banach spaces. Nonlinear Anal. 68, 2977-2983 (2008). doi:10.1016/.jna.2007.02.041

6. Suzuki, T: On strong convergence to common fixed points of nonexpansive semigroups in Hilbert spaces. Proc Am Math Soc. 131, 2133-2136 (2003). doi:10.1090/S0002-9939-02-06844-2

7. $\mathrm{Xu}, \mathrm{HK}$ : A strong convergence theorem for contraction semigruops in Banach spaces. Bull Aust Math Soc. 72, 371-379 (2005). doi:10.1017/S000497270003519X

8. Chang, SS, Yang, L, Liu, JA: Strong convergence theorem for nonexpansive semigroups in Banach spaces. Appl Math Mech. 28, 1287-1297 (2007). doi:10.1007/s10483-007-1002-x

9. Zhang, SS: Convergence theorem of common fixed points for Lipschitzian pseudo-contraction semigroups in Banach spaces. Appl Math Mech (English Edition). 30(2):145-152 (2009). doi:10.1007/s10483-009-0202-y

10. Cho, SY, Kang, SM: Approximation of fixed points of pseudocontraction semigroups based on a viscosity iterative process. Appl Math Lett. 24, 224-228 (2011). doi:10.1016/j.aml.2010.09.008

11. Qin, X, ChO, SY: Implicit iterative algorithms for treating strongly continuous semigroups of Lipschitz pseudocontractions. Appl Math Lett. 23, 1252-1255 (2010). doi:10.1016/j.aml.2010.06.008

12. Agarwal, RP, Qin, X, Kang, SM: Strong convergence theorems for strongly continuous semigroups of pseudocontractions. Appl Math Lett. 24, 1845-1848 (2011). doi:10.1016/j.aml.2011.05.003

doi:10.1186/1687-1812-2012-16

Cite this article as: Quan et al.: Strong and weak convergence of an implicit iterative process for pseudocontractive semigroups in Banach space. Fixed Point Theory and Applications 2012 2012:16.

\section{Submit your manuscript to a SpringerOpen ${ }^{\odot}$} journal and benefit from:

- Convenient online submission

- Rigorous peer review

- Immediate publication on acceptance

- Open access: articles freely available online

- High visibility within the field

- Retaining the copyright to your article

Submit your next manuscript at $\gg$ springeropen.com 